\title{
Case Report \\ Orthodontic Elastic Separator-Induced Periodontal Abscess: A Case Report
}

\author{
Talia Becker $^{1}$ and Alex Neronov ${ }^{2}$ \\ ${ }^{1}$ Department of Oral Pathology and Oral Medicine, The Maurice \& Gabriela Goldschleger School of Dental Medicine, \\ Tel Aviv University, Tel Aviv, Israel \\ ${ }^{2}$ Israel Defense Forces, Medical Corps, Israel
}

Correspondence should be addressed to Talia Becker, becktalia@gmail.com

Received 12 September 2011; Accepted 10 October 2011

Academic Editors: C. A. Evans and T. Lombardi

Copyright (C) 2012 T. Becker and A. Neronov. This is an open access article distributed under the Creative Commons Attribution License, which permits unrestricted use, distribution, and reproduction in any medium, provided the original work is properly cited.

Aim. Orthodontic elastic bands were proposed as being the source of gingival abscesses that can rapidly lead to bone loss and teeth exfoliation. We report an adolescent, otherwise, healthy patient whose periodontal status was sound. Shortly after undergoing preparations for orthodontic treatment consisting of orthodontic separators, he presented with a periodontal abscess for which there was no apparent etiology. A non-orthoradial X-ray was inconclusive, but an appropriate one revealed a subgingival orthodontic separator as the cause of the abscess. Removal of the separator and thorough scaling led to complete resolution of the abscess, but there was already residual mild damage to the alveolar bone. Summary. Failure to use appropriate imaging to reveal the cause of gingival abscesses can result in the delay of implementing treatment and halting irreversible alveolar bone loss. An inflammatory process restricted to the gingiva and refractive to conventional therapy should raise the possibility of a foreign body etiology.

\section{Introduction}

Local anatomic and iatrogenic factors may promote plaque retention and proliferation of microorganisms in the periodontal pocket, resulting in progressive inflammatory changes [1]. An inflammatory process restricted to the gingiva and refractive to conventional therapy should raise the possibility of a foreign body etiology [2]. Several reported cases of bone loss and teeth exfoliation were reported in association with orthodontic elastic bands [3-5], especially when they had been used to close a midline diastema between maxillary incisors. However, there are only a few reported cases of periodontal destruction caused by displaced orthodontic separators [6, 7]. Commonly employed therapeutic modalities include a combination of laser treatment, antibiotics, splinting, and orthodontics [8]. In order to avoid complications, it was recommended to use brightly colored elastic bands and to remove them after two weeks [9]. This report describes a case of a periodontal abscess associated with a displaced orthodontic separator and emphasizes the importance of appropriate X-rays for accurate diagnosis.

\section{Case Report}

A 19-year-old patient was referred for evaluation of a painful swelling on the buccal aspect of the gingiva of the mandibular left first molar. The patient reported becoming aware of the swelling approximately two days prior to his arrival to the clinic. The swelling was accompanied by white ulcers the size of pinheads (Figure 1). His medical history was unremarkable, and he was free of systemic symptoms (e.g., lymphadenitis, malaise, fever, or skin lesions). He had recently undergone initial preparations for planned orthodontic treatment for crowding.

The first X-ray was not orthoradial, and it revealed a small ill-defined radio-opaque area on the mesial aspect of the interproximal alveolar crest (Figure 2(a)). An additional X-ray from an orthoradial angle clearly displayed the 


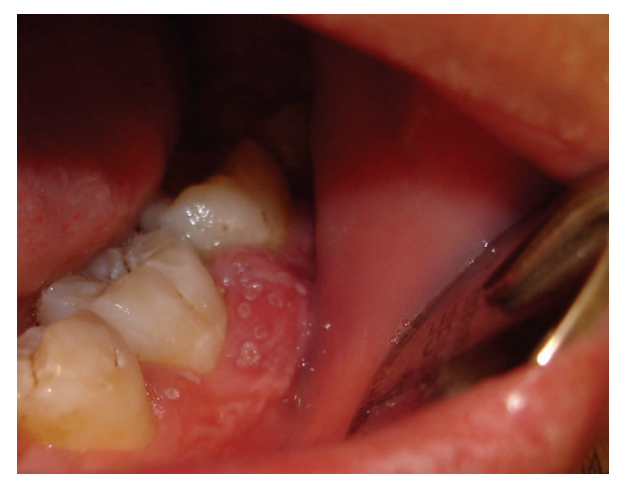

FIgURE 1: Clinical view of the periodontal abscess of the gingiva buccal attached to the lower left first molar and involving the adjacent papillae.

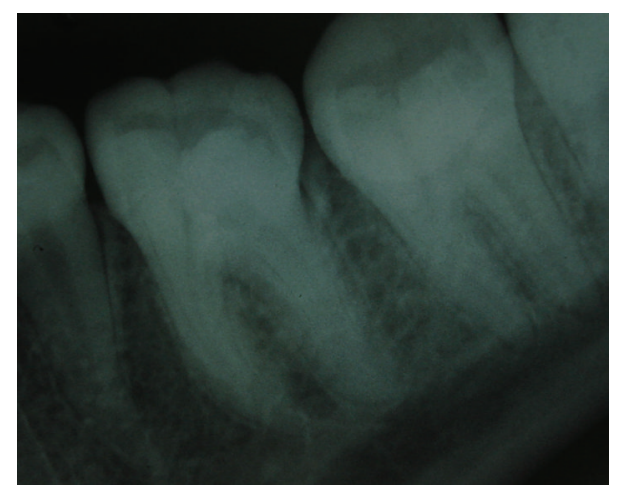

(a)

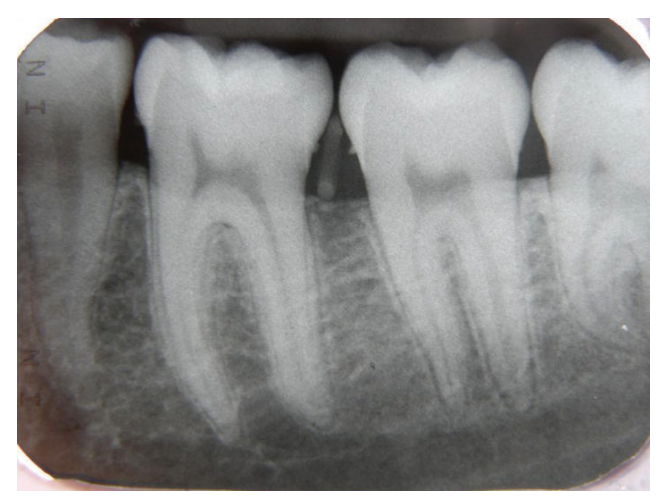

(b)

Figure 2: (a) Radiographic view of the elastic rubber band between the first and second lower left molars. (b) A proper periapical X-ray revealing an elastic band in the periodontal space.

interproximal area in which a radio-opaque, rectangularshaped mass was discernable, as was subgingival calculus (Figure 2(b)). The elastic rubber band was removed by periodontal curettage. The clinical appearance at the onemonth follow-up indicated complete recovery of the soft tissue (Figure 3), but the radiographic view revealed residual alveolar bone loss (Figure 4).

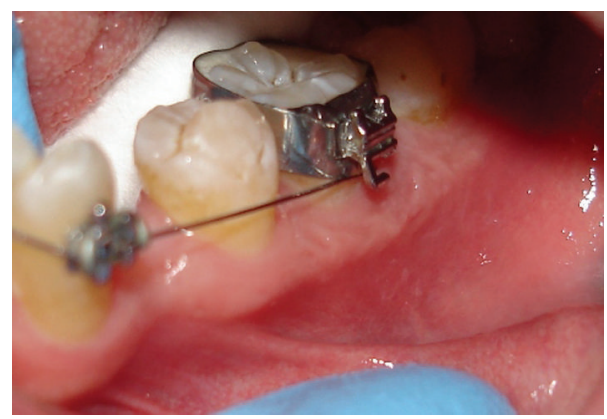

Figure 3: Clinical features at the one-month posttreatment followup with no clinical demonstration of residual pathology.

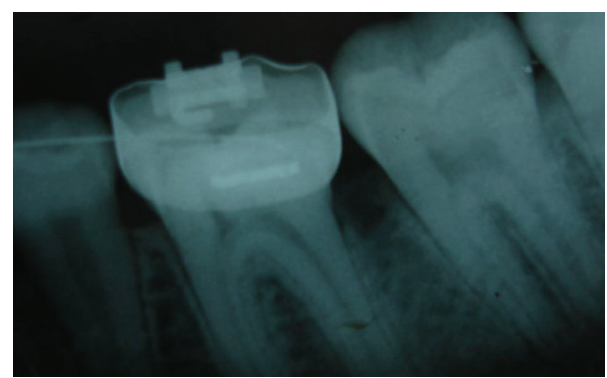

FIGURE 4: Radiographic view one month following treatment demonstrating damage to the alveolar bone between the first and second lower left molars.

\section{Discussion}

The present report emphasizes the need for appropriate imaging to diagnose pathological conditions of the periodontium. It also highlights potential risks to the periodontium caused by using orthodontic elastic bands. Localized periodontitis and periodontal abscesses can be associated with a variety of dental material, such as silicone impression materials $[10,11]$, rubber dam [12], and even selfinflicted gingival injury due to habitual fingernail biting [13]. Localized reactive overgrowths of the gingiva can include the differential diagnoses of pyogenic granuloma [14-17], peripheral giant cell granuloma [14, 17], and periodontal abscess [17]. They can result from the invasion of pyogenic bacteria through the pocket epithelium, secondary to microtrauma or blockage of flow of inflammatory exudates from within the periodontal pocket. Entrapment of foreign bodies may serve as a trigger for these events [17, 18]. Several millimeters of periodontal attachment and alveolar bone can be lost within as little as a few days. The onset is sudden and accompanied by an acute inflammatory response (purulence) during which tissue necrosis takes place [17]. A painful gingival swelling may occur anywhere around the affected teeth. Swelling might involve the vestibule or cheek, since pus follows the path of least resistance. Depending on the severity of the infection, the patient may experience regional lymphadenitis, malaise, or fever. Such circumstances can represent a true emergency situation [17].

Foreign material may cause and aggravate gingival lesions $[2,18]$. A foreign body might induce both inflammatory and 
noninflammatory gingival changes manifested clinically as swelling and/or discoloration [2]. Koppang et al. [2] found that the mandibular and maxillary posterior segments were most frequently affected with foreign body gingival lesions (34\% and $29 \%$, resp.), followed by the maxillary anterior region (26\%) [2]. They commented that these findings are probably attributable to the high frequency of dental procedures in these segments. Elastic bands should not be used on crowns of teeth without provision for stabilization [3]. A rubber band that slips undetected under the gingiva might move along the roots, resulting in significant loss of alveolar bone [3].

Foreign body-induced reaction should be included in the differential diagnosis of gingival overgrowths. Periodontal abnormalities occurring when orthodontic elastic separators are used should raise the possibility of a band impinging into the biological width. Appropriate imaging is essential for accurate diagnosis, especially when those devices are radiopaque.

\section{References}

[1] L. Jansson, H. Ehnevid, S. Lindskog, and L. Blomlöf, "Proximal restorations and periodontal status," Journal of Clinical Periodontology, vol. 21, no. 9, pp. 577-582, 1994.

[2] H. S. Koppang, A. Roushan, A. Srafilzadeh, S. Ø. Stølen, and R. Koppang, "Foreign body gingival lesions: distribution, morphology, identification by X-ray energy dispersive analysis and possible origin of foreign material," Journal of Oral Pathology and Medicine, vol. 36, no. 3, pp. 161-172, 2007.

[3] W. F. Waggoner and K. D. Ray, "Bone loss in the permanent dentition as a result of improper orthodontic elastic band use: a case report," Quintessence International, vol. 20, no. 9, pp. 653-656, 1989.

[4] N. I. Zager and M. L. Barnett, "Severe bone loss in a child initiated by multiple orthodontic rubber bands: case report," Journal of Periodontology, vol. 45, no. 9, pp. 701-704, 1974.

[5] Y. Zilberman, A. Shteyer, and B. Azaz, "Iatrogenic exfoliation of teeth by the incorrect use of orthodontic elastic bands," The Journal of the American Dental Association, vol. 93, no. 1, pp. 89-93, 1976.

[6] Z. Harrington and U. Darbar, "Localised periodontitis associated with an ectopic orthodontic separator," Primary Dental Care, vol. 14, no. 1, pp. 5-6, 2007.

[7] G. St George and M. A. Donachie, "Case report: orthodontic separators as periodontal ligatures in periodontal bone loss," The European Journal of Prosthodontics and Restorative Dentistry, vol. 10, no. 3, pp. 97-99, 2002.

[8] R. L. Finkbeiner, L. S. Nelson, and J. Killebrew, "Accidental orthodontic elastic band-induced periodontitis: orthodontic and laser treatment," Journal of the American Dental Association, vol. 128, no. 11, pp. 1565-1569, 1997.

[9] W. R. Proffit and H. W. Fields, Contemporary Orthodontics, Mosby, St. Louis, Mo, USA, 3rd edition, 1999.

[10] T. J. Giusto, "Localized severe periodontitis associated with retained impression material and root proximity: report of a case," Journal of the New Jersey Dental Association, vol. 77, no. 4, pp. 39-40, 2006.

[11] Z. D. Klein and J. Shiloah, "Retained silicone impression material associated with a periodontal abscess," Mississippi Dental Association Journal, vol. 55, no. 3, pp. 40-41, 1999.
[12] Greenbaum and H. E. Strassler, "Periodontal complications following use of the rubber dam: a case report," Operative Dentistry, vol. 19, no. 5, pp. 162-164, 1994.

[13] C. B. Krejci, "Self-inflicted gingival injury due to habitual fingernail biting," Journal of Periodontology, vol. 71, no. 6, pp. 1029-1031, 2000.

[14] F. G. Salum, L. S. Yurgel, K. Cherubini, M. A. De Figueiredo, I. C. Medeiros, and F. S. Nicola, "Pyogenic granuloma, peripheral giant cell granuloma and peripheral ossifying fibroma: retrospective analysis of 138 cases," Minerva Stomatologica, vol. 57, no. 5, pp. 227-232, 2008.

[15] W. Zhang, Y. Chen, Z. An, N. Geng, and D. Bao, "Reactive gingival lesions: a retrospective study of 2,439 cases," Quintessence International, vol. 38, no. 2, pp. 103-110, 2007.

[16] S. Prasad, S. B. Reddy, S. R. Patil, N. B. Kalburgi, and R. S. Puranik, "Peripheral ossifying fibroma and pyogenic granuloma. Are they interrelated?" The New York State Dental Journal, vol. 74, no. 2, pp. 50-52, 2008.

[17] J. A. Regezi and J. J. Sciubba, Oral Pathology, WB Saunders, Philadelphia, Pa, USA, 2nd edition, 1993.

[18] S. C. Gordon and T. D. Daley, "Foreign body gingivitis. Clinical and microscopic features of 61 cases," Oral Surgery, Oral Medicine, Oral Pathology, Oral Radiology \& Endodontics, vol. 83, pp. 562-570, 1997. 


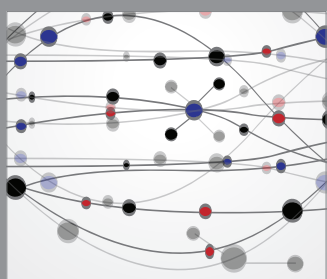

The Scientific World Journal
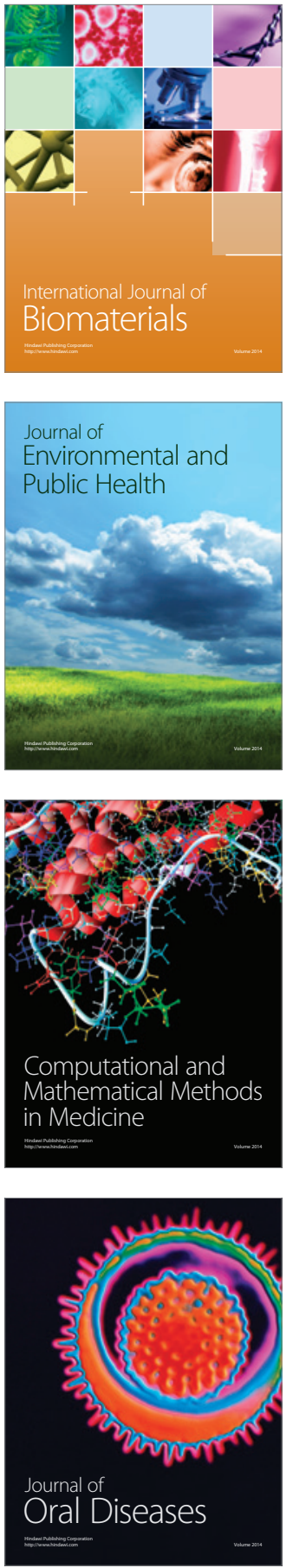
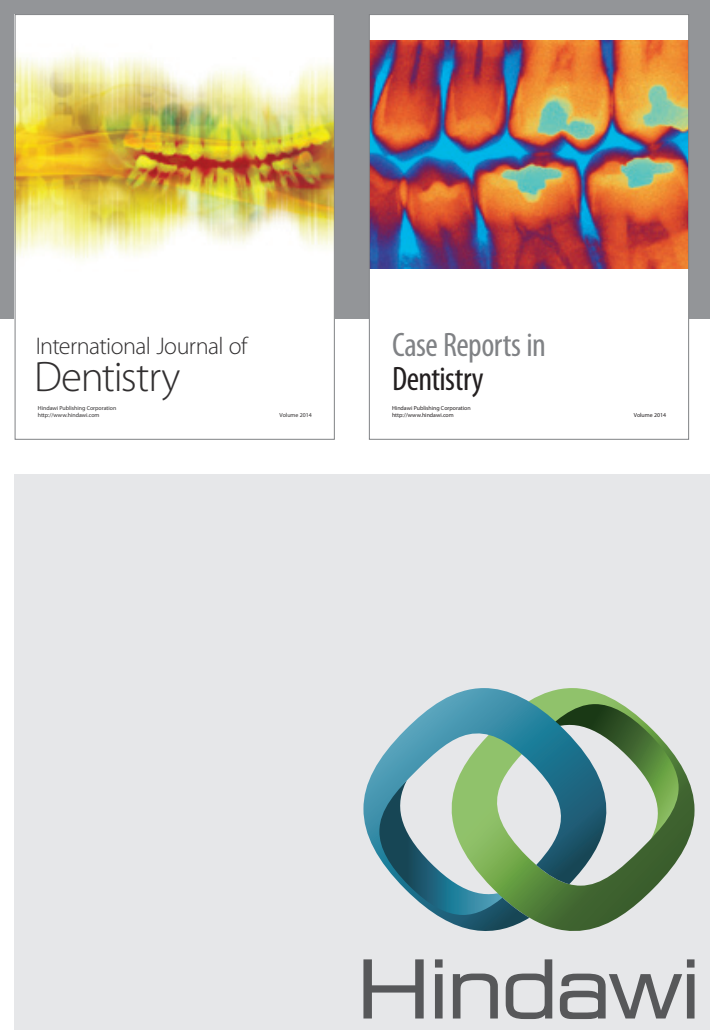

Submit your manuscripts at

http://www.hindawi.com
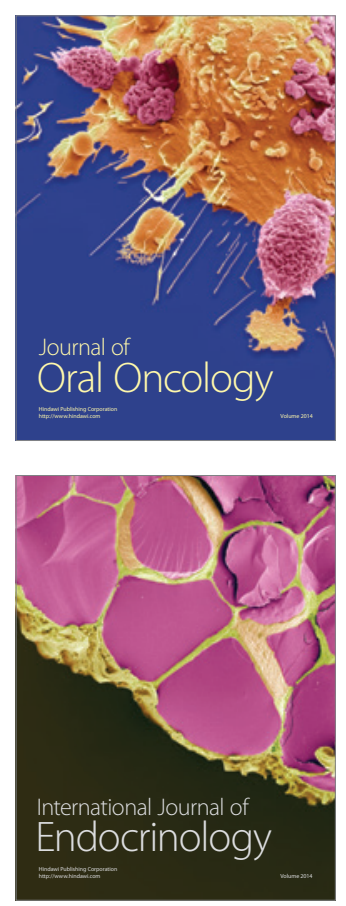
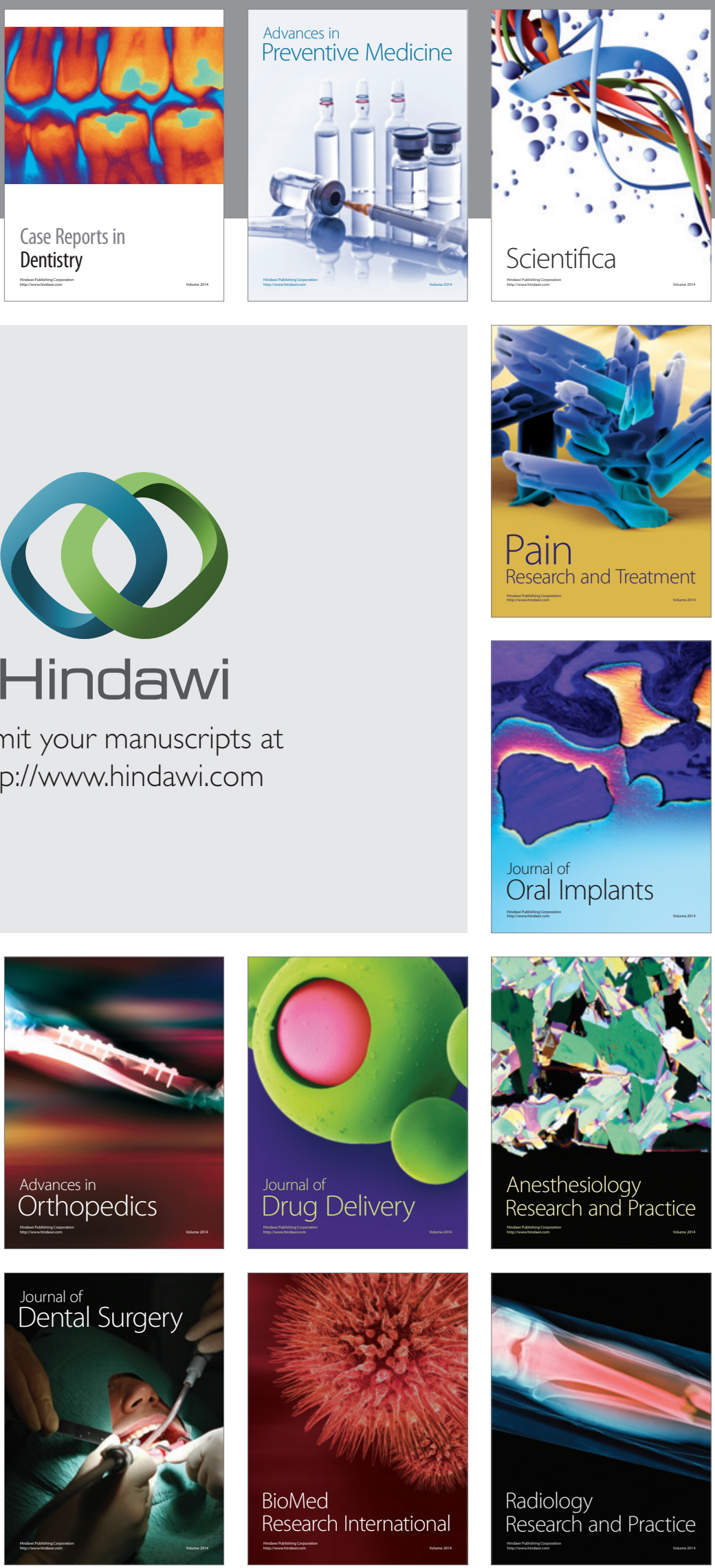